Revista de la red interuniversitaria de estudios sobre las literaturas rioplatenses contemporáneas en Francia

Un año. Literatura argentina 1969

\title{
Literatura latinoamericana, meridiano argentino, pasiones críticas
}

\section{Teresa Orecchia Havas}

\section{OpenEdition \\ Journals}

Edición electrónica

URL: http://journals.openedition.org/lirico/3115

DOI: 10.4000/lirico.3115

ISSN: 2262-8339

Editor

Réseau interuniversitaire d'étude des littératures contemporaines du Río de la Plata

\section{Referencia electrónica}

Teresa Orecchia Havas, «Literatura latinoamericana, meridiano argentino, pasiones críticas », Cuadernos LIRICO [En línea], 15 | 2016, Puesto en línea el 05 octubre 2016, consultado el 01 mayo 2019. URL : http://journals.openedition.org/lirico/3115; DOI : 10.4000/lirico.3115

Este documento fue generado automáticamente el 1 mayo 2019.

\section{(c) $(1) \ominus$}

Cuadernos LIRICO está distribuido bajo una Licencia Creative Commons Atribución-NoComercialSinDerivar 4.0 Internacional. 


\title{
Literatura latinoamericana, meridiano argentino, pasiones críticas
}

\author{
Teresa Orecchia Havas
}

A Buenos Aires, en el tiempo.

\section{Hacia el pasado}

1 Lo cierto es que el año 1969 transcurrió (ocurrió?) hace ... un siglo. ¿Qué éramos, qué hacíamos entonces? ¿Qué nos pasó al fin de esos años sesenta que se volvieron legendarios y fueron vistos como una etapa exaltante, rápida, única, desde el mirador de las décadas que los siguieron? Éste no es lugar para entregarse a testimonios o a anécdotas personales y esas preguntas quedarán por el momento sin respuesta, pero aun silenciosamente, no dejarán de rondar las páginas que siguen, riesgo del que escribe sobre tiempos que fueron también los suyos.

2 Vivimos hoy una época en la que la moda de la memoria o de lo memorial, la obsesión del pasado, no obstante las críticas a las que se la somete, sigue cundiendo, de manera contradictoria, junto a los arduos ejercicios de olvido que tantas veces se han considerado indispensables para la superación de los conflictos contemporáneos. Días de "presentismos", de aceleración, de culto de la fugacidad (Bauman, Huyssen, Hartog), nuestros tiempos piensan también la superposición de las temporalidades, lo “intempestivo" (Agamben) y lo anacrónico que anidan en eso que llamamos presente. Las producciones culturales, y la literatura y la crítica entre ellas, afectadas por la presión del presente, pero también determinadas por una inserción compleja e inestable en construcciones historicistas, apelan con fuerza al análisis de la relación entre las estéticas y las crisis del tiempo social, así como a la reflexión sobre periodicidades y anacronismos o sobre la posible autonomía de los discursos críticos.

3 Aceptemos el desafío y vayamos por lo tanto hasta Buenos Aires en 1969: en abril de ese año aparece con sello de Paidós Nueva novela latinoamericana 1, una recopilación de 
artículos sobre la literatura latinoamericana reciente, seguida tres años después por un segundo volumen, consagrado a la literatura argentina, ambos bajo la responsabilidad de Jorge Lafforgue, crítico, periodista, director de colecciones editoriales ${ }^{1}$. Creo que esta obra de formato entonces poco frecuente vale como una marca estable impresa en el mapa de intentos críticos en forma de panorama surgidos en ese período, y que vale la pena revisar su lugar y sus contextos hoy, a distancia de varias décadas, porque ambos explicitan tensiones del campo literario en las que arraiga también la primera parte de los decisivos años setenta, así como anticipan el papel de algunos de sus actores principales.

El fin de los sesenta es una época pródiga en contrastes sociales, un momento de cruce entre un impulso optimista acelerado por las facilidades del consumo y el peso de estructuras económicas cuya modernización se había cumplido a medias. En el plano de la creación y la difusión literarias el episodio más ostensible es la mayor visibilidad de una literatura continental que parece aportar nuevas propuestas, mientras que del lado argentino surgen los primeros signos de diversas sensibilidades neo-vanguardistas que se afianzarán diez años más tarde. Por sus fechas, por los nombres de ciertos protagonistas, por las líneas de análisis que éstos practican, el proyecto de Lafforgue tiene contactos con el nacimiento de un discurso crítico radical que emerge de manera programática en los primeros años setenta y tiene su exponente más claro en la revista Los libros ${ }^{2}$. En consecuencia, al menos tres campos merecen comentario en relación con la presencia de esos dos volúmenes en el horizonte del fin de los sesenta: el impacto de la literatura latinoamericana que viene afirmándose desde principios de la década, la situación de la Argentina, las ambiciones de la crítica.

\section{Literatura latinoamericana}

Los sesenta son los años de ascensión y consagración de las nuevas promociones de autores del continente, algunos de los cuales, brillantes narradores, animaron y protagonizaron el fenómeno literario-mediático-publicitario al que se dio el nombre de boom de la literatura latinoamericana, un proceso literario inaudito que habría durado unos ocho o nueve años, a partir de $1964^{3}$. La tarea de cernir el proceso en su exacta cronología parece ingrata, pero hay algunos parámetros de su gestación que han sido en general aceptados. En particular, se reconoce el papel que cumplieron las revistas de circulación masiva, que se modernizaron y aumentaron su número en los años sesenta en capitales como Buenos Aires o México y que fueron protagonistas en la difusión de los nuevos autores ante un público que se había ampliado considerablemente como consecuencia del alza de los niveles de vida, de educación y de consumo en las décadas de los cincuenta y sesenta. En la Argentina, el más conocido es quizás el caso del semanario Primera Plana $a^{4}$ la revista porteña desde cuyas columnas de reseñas y análisis cultural se difundió y se impulsó la nueva narrativa latinoamericana, revista semanal que contaba con un grupo de periodistas y críticos informados, actualizados y conocedores del oficio de las letras -el muy activo Tomás Eloy Martínez entre otros-.

Si agentes distintos que los tradicionales ocupan entonces el espacio de crítica y difusión de la literatura latinoamericana desde los medios masivos, también surgen, en otros lugares que Buenos Aires, revistas especializadas de inflexión nueva que representan los procesos mayores que afectan al campo literario. Dos casos antagónicos, geográfica y políticamente, dominan el panorama en los sesenta: Casa de las Américas desde La Habana, que recaba el prestigio de la revolución cubana y la notoriedad de sus intelectuales, y 
Mundo Nuevo desde Paris, que en su primera etapa, bajo la dirección de Emir Rodríguez Monegal, difunde mensualmente con entusiasmo a los nuevos autores, algunos de los cuales, como Severo Sarduy o Cabrera Infante, crearán lenguajes auténticamente renovadores. Como lo recuerda John King (1986: 179-187), a nivel continental son estas dos revistas las que ocupan el lugar que Sur, ciega ante la revolución social y sin posibilidades reales de superar las limitaciones de su historia editorial, no puede ya ocupar en la escena de las letras latinoamericanas 5 .

7 Mundo Nuevo, la publicación especializada que circulaba libremente desde julio de 1966 (número 1) y se aplicaba a dar a conocer la literatura latinoamericana a través de la inserción de textos originales, de ensayos críticos y de la entrevista a autores, lo hacía en particular en esa zona que fue identificada como el fenómeno del boom. Detrás de éste no había sin embargo un programa, ni una estética compartida, ni un frente de autores que se reconocieran en posiciones comunes o que ofrecieran un cuadro homogéneo en lo generacional ${ }^{6}$. Por eso, si bien desde sus inicios se discuten los parámetros en los que se puede englobar el proceso ${ }^{7}$, su rasgo quizás más consensual se puede fijar en una sola fórmula, "el consumo masivo de narraciones latinoamericanas" (Rama 1981: 64) dentro de un panorama de lecturas que había sido hasta entonces de una insigne pobreza (Donoso 1972). En efecto, la más que modesta actualidad de los autores latinoamericanos contemporáneos hasta este momento puede verse a través de casos como el de Asturias, que residió largo tiempo en Buenos Aires, y a quien se puede considerar como una figura emblemática de cierta revolución en el imaginario y en la lengua de la narrativa del continente a partir de los años treinta. Asturias recibió su carta de mayor visibilidad internacional e intercontinental, el premio Nóbel, recién en 1967, el mismo año de la publicación de Cien años de soledad por Sudamericana. Hasta entonces sus libros eran leídos en Buenos Aires por un público restringido, aun cuando el nombre tuviera autoridad y las novelas fueran publicadas por la editorial Losada desde finales de los años 40 (la primera edición de Hombres de maíz es de 1949; la segunda de El Señor Presidente de 1952). ${ }^{8}$ En cuanto al ámbito académico, se podría mencionar una impertérrita tradición de estudios de lo absolutamente consagrado por la historia literaria del continente (cronistas, textos costumbristas y regionalistas, modernismo) que dejaba totalmente fuera de concurso las producciones recientes ${ }^{9}$. Así es como el programa de Literatura hispanoamericana de la carrera de Letras dictado por Enrique Pezzoni en el año 1966 fue considerado casi como una maniobra revolucionaria. Estaba centrado en torno a Asturias, Neruda y Octavio Paz, autores que eran una completa novedad en el cursus de los estudiantes.

Pero es evidente que otros factores, culturales y políticos, deben ser tomados en cuenta para una mejor comprensión del contexto argentino ${ }^{10}$. En la Argentina al menos, el descubrimiento de los autores latinoamericanos (en lo fundamental García Márquez, Vargas Llosa y Carlos Fuentes) se produjo en un momento en que los ojos y la imaginación del público comenzaban a abrirse a lo que podría llamarse "el continente" y en que la habitual percepción de las culturas americanas como exóticas o sin gran interés para la narcisista cultura urbana porteña se matizaba con una visión a la vez más abierta, curiosa y tolerante. Si los medios de comunicación y las consumidoras clases medias urbanas eran los actores principales de este cambio, éstos se encontraron progresiva y contradictoriamente acompañados por sus co-autores, las izquierdas y los jóvenes. El giro era todavía incipiente a mediados de los sesenta, pero ya estaba bien inscripto en las mentalidades de los intelectuales y estudiantes universitarios, así como en los catálogos 
de algunos editores locales (sobre todo Losada, Fabril, Sudamericana). El peronismo renaciente de fines de la década y más aún de principios de los setenta contenía por su parte una vertiente fuertemente americanista; sus juventudes (y no sólo la franja de ellas que se inspiraba directamente en la revolución cubana) no querían volver la espalda al continente, y la bandera tercermundista implicaba necesariamente que se tomara en cuenta a los "hermanos" de los países vecinos. Desde un punto de vista atento a la historia política quizás haya que pensar este brote de solidaridad continental como una secuela de las ambiciones al liderazgo internacional del viejo peronismo de Perón, con su defensa de la tercera posición y su propuesta sobre los países no alineados, aunque de manera más inmediata obedecía en los setenta a la ola de pensamiento internacionalista que acarreaba el conjunto de las ideologías de izquierda así como al fermento de la revolución cubana. Es dentro de ese panorama de contrastes sociológicos y de agitación política que las revistas y las editoriales inducen cambios y dan testimonio de la evolución de las percepciones colectivas ${ }^{11}$. Aparecen editoriales pequeñas y medianas, se publican libros baratos, se apunta a nuevos sectores de público lector de literatura (por ejemplo, los estudiantes) ${ }^{12}$.

9 En este contexto, los volúmenes de Nueva novela latinoamericana pueden considerarse como una empresa totalmente en fase con la década que clausuran y como una novedad en el panorama editorial que confirma a las letras latinoamericanas recientes en tanto objeto serio de estudio. Si bien el objetivo de Lafforgue es impulsar la nueva narrativa, está claro que trabaja con un afirmado criterio historicista. No hay que olvidar por otra parte que su elección de separar la literatura argentina de la del resto del continente no es un gesto aislado ni mucho menos en la cultura local. Tanto en revistas literarias que surgieron poco más tarde, afiliadas a cierto latinoamericanismo populista, por ejemplo $\mathrm{Crisis}^{13}$, como en los semanarios destinados a una franja supuestamente culta, progresista y acomodada de la población urbana (Primera Plana, Panorama, etc.) o en las políticas editoriales, la literatura argentina sigue siendo vista y tratada por críticos, periodistas y gente del libro a la manera de una producción con características y tradición propios. A lo sumo se vería como perteneciente al mismo ámbito cultural a la literatura uruguaya, y sólo en parte, a la chilena (vuelta de pronto más familiar a principios de los 70 también a causa del acuerdo ideológico con el régimen de Allende) ${ }^{14}$. En el caso de un autor como Onetti (o incluso como Felisberto Hernández unos pocos años más tarde), por ejemplo, su surgimiento entre los nuevos narradores celebrados por los críticos es en verdad un redescubrimiento, que lo desplaza desde los años 40 y 50 de sus primeros libros y lo pone en contacto con las literaturas de las dos décadas posteriores, preocupadas por la transformación del discurso narrativo, pero siempre dentro del contexto intelectual, social y estético del Río de la Plata ${ }^{15}$.

10 Al intentar una breve caracterización del período -fines de los sesenta, comienzos de los setenta- de tonos claramente valorativos, Luis Chitarroni no olvida señalar la diferencia argentina:

La prédica del boom impone un primer nivel: legibilidad a primera vista a pesar de los procedimientos del autor. Al fin de cuentas, después de Borges, la literatura argentina al menos sabía de argucias y brevedades que encerraban infinitos, de saltos temporales y fuentes remotas, de oscuridades que se iban aclarando luego con precisión meridiana. [...] Tal vez haya que pensar en la gravitación del boom como en cualquiera de esas supersticiones populares que nunca se dejan domesticar por la razón. $\mathrm{O}$ al revés: tal vez haya que pensarlo como un momento de madurez de la narrativa latinoamericana que excluye cualquier emergencia experimental, una 
clausura total de la vanguardia, un maduro certamen de avezados. No una

superstición sino una mecánica popular (2000: 163-164, 167).

11 Podemos pensar que esta opinión representa cierto consenso crítico de hoy y cierta reticencia de siempre en torno a la relación entre el tiempo y los programas de la "nueva" literatura latinoamericana comparados a los de la literatura argentina. Tres razones de reproche al brote latinoamericano y a su aura son claramente legibles aquí: una estética caracterizada por un imperativo general de transparencia, es decir, de representación e inteligibilidad, ya abundantemente hostigadas por la prestigiosa línea argentina de textos especulativos; un relente de irracionalidad y de cosa efímera; una clausura del espíritu experimental. El nombre de Borges no viene al caso en vano: para el crítico, la tan mentada eclosión de nuevos narradores (García Márquez parece estar bien presente en la alusión) traía recetas que llegaban tarde para los argentinos, que llegaban después de todo lo que Borges les había enseñado, y que contradecían las más caras ambiciones (o "supersticiones") literarias de éstos: hacer siempre obra de vanguardistas. Vistos desde Buenos Aires, los exitosos escritores latinoamericanos habrían animado un acontecimiento cuyos vectores estéticos y preocupaciones procedían de las tradiciones literarias nacionales de otros países u otras regiones, más que de las del Plata, si bien la cultura rioplatense (y en primer término, los lectores) se mostraría en los años mismos del fenómeno puntualmente abierta al contacto con autores y obras ${ }^{16}$. Si el período es inseparable del despertar de un interés internacional antes desconocido por los productos de la narrativa latinoamericana ${ }^{17}$, en la idea de una inédita recepción "internacional" habría que incluir, además de los meridianos europeo y norteamericano, a esa zona intermediaria y de reacciones mucho más ambiguas que es la que irradia la cultura porteña.

\section{La provincia argentina: autores, obras, grupos neo- vanguardistas}

12 Echemos ahora un vistazo a las líneas que habitaban y definían la literatura argentina de los sesenta-setenta, en la que, si bien el influyente corpus borgeano gozaba aún de prestigio pleno, y los escritores que se le podían asociar, como Bioy Casares, seguían publicando y conservaban su público, las mutaciones de la industria cultural y la fuerte impregnación ideológica de los intelectuales alejaban cada vez más las mentalidades de los mundos sofisticados del maestro y de sus modos de interpretación de la realidad.

¿Qué se publica entonces en la Argentina? ¿Qué obras, qué poéticas, se preparan a afianzarse más tarde? Operación masacre, que introduce una radical desestabilización de los géneros, data de 1957, pero el libro se reimprime varias veces y su mayor auge tiene que ver con el renacimiento del peronismo al principio de los 70 (la tercera edición es de 1969, la cuarta, así como la película homónima de Jorge Cedrón son de 1972); Libertella firma El camino de los hiperbóreos, experimental y lúdica, en 1968; Viñas entrega Cosas concretas en 1969; Quién mató a Rosendo? (Walsh) es también de ese año, lo mismo que Cicatrices (Saer) y El Fiord, el primer libro, extremadamente revulsivo pero de circulación más que restringida, de Osvaldo Lamborghini. Manuel Puig irrumpe con La traición de Rita Hayworth en 1968; Boquitas pintadas aparece en 1969; The Buenos Aires Affair en 1973. 1969 es también un año en que está todavía fresca la tinta del proceso intentado a Nanina, de Germán García, indicio neto de los límites que aun pone el celo de la moral pública a la literatura. Claro está que hay también muestras de estéticas que no son afiliables a lo 
novedoso, como la novela de Bioy Casares Diario de la guerra del cerdo (1969), o escrituras originales poco abordadas por la crítica, como la de Elvira Orphée (En el fondo, 1969), u obras de autores que serán como explosivas estrellas fugaces en el cielo de la literatura argentina, como El amhor, los Orsinis y la muerte (1969), de Néstor Sánchez, o incluso ejemplos de libros de relativo éxito en el mercado de lectores, como Heroína (1969) de Emilio Rodrigué, que han sido totalmente olvidados después. Como lo ha señalado Dalmaroni (2005), el catálogo de 1969 obliga a reelaborar la perspectiva de la coincidencia de calendario: ciertos autores que alcanzarán luego sólida confirmación como Saer ( Cicatrices) son vecinos de otros cuyas poéticas no son novedosas, como Di Benedetto (Los suicidas), son endebles, o se perciben como correspondientes a otras tradiciones, como en el caso de Tomás Eloy Martínez (Sagrado).

En las décadas siguientes la crítica se aplicará a levantar sucesivas listas de escritores emblemáticos de los primeros setenta; hoy, el balance sigue inclinándose hacia Puig, Walsh, Libertella y el provocativo Lamborghini, que cobra rápida estatura de maestro oculto (de breve obra) entre algunos de sus pares. En uno de sus artículos más penetrantes, que mira hacia atrás con los ojos impregnados en los 70, Rama (1982) llegaba a postular a Walsh como el verdadero heredero de Borges, porque en su obra, como en la de este último, se moderniza el discurso de la literatura por la mezcla de elementos de bajo origen con componentes genéricos nobles. Un rasgo que en verdad se puede considerar como una característica de la literatura de la época y como una tensión más o menos constante en la tradición argentina.

Daniel Link observa oportunamente: "Si hay algo que define el pasaje de los sesenta a los setenta es la irrupción de fuerzas antiestéticas en el arte. Los textos de Rodolfo Walsh [...] señalan el punto de corte y disolución de la lógica ficcional dominante hasta ese momento, deshacen la novela como género y ponen en crisis la institución literaria" (Link 2006: 110). Walsh sería el ejemplo más puro de la fascinación por las prácticas de la industria cultural (traducciones, periodismo), al tiempo que encabezaría el impulso a la disolución del arte y a la transformación de los géneros por la violencia de la política ${ }^{18}$. La hipótesis más abarcadora de Link, con la que coinciden otros críticos y que ya no necesita mayor demostración, es que hay en la literatura argentina del sesenta y el setenta un notable doble sesgo político/estético que constituye su gran novedad. La literatura de los primeros setenta acentúa esas pautas colocando la violencia en el centro de sus preocupaciones y apelando para representarla a un uso transgresivo del discurso y de la lengua ${ }^{19}$. Si se politizan las representaciones también se estetiza lo político, la política afecta, permea, la prosa. Lógicamente, los escritores de la época parecen haber mantenido, frente a la eclosión de obras latinoamericanas impulsadas por un mercado internacional y firmadas por nombres rápidamente consagrados, una "relación de extraña fascinación y distancia" (Link: 115).

Una meditación sobre los mass media acompaña por otro lado las estrategias críticas de esos años. En general, esta meditación es de cuño optimista ${ }^{20}$, pero un autor como Saer, ya desde su atalaya europea, los piensa como contexto inevitable de una literatura degradada y los ataca en consecuencia, sobreentendiendo en su ataque que los escritores del boom aprovechan de ellos de manera irreflexiva, y que están afiliados a un uso irresponsable de los estereotipos. Un artículo de 1969, "La literatura y los nuevos lenguajes", sintetiza sus ideas:

Se puede decir que, al menos desde 1950, los mass media instalaron, en lugar de la escritura, el reino del estereotipo, del arte de segunda mano, de la tautología oficial, 
de la fraseología hueca que repite, con una servilidad calculada, las simplificaciones

de los verdugos y de los mercaderes. ${ }^{21}$ nuevas narrativas latinoamericanas, aproximadamente una década (1964-1974) ${ }^{22}$, coincide con una evolución de la industria cultural local que lleva a un consumo mayor de lecturas y de literatura, colocadas o no bajo la enseña sociológico-publicitaria del boom. Pero esa breve década presencia y produce, simultáneamente, una intensa politización de la cultura, una des-estructuración de ciertas formas tradicionales del relato (Walsh), una novedosa utilización del imaginario y de los lenguajes de los medios (Puig), una búsqueda acérrima de discursos subversivos y de conversión de la norma lingüística culta en códigos bajos (Lamborghini y otros). No es entonces contradictorio que la mirada que se dirige al estallido de escritura latinoamericana desde el meridiano argentino esté determinada por la evaluación irónica del mundo de lo "real maravilloso", de los ejercicios de realismo mágico con final feliz a los que se piensa que se entregan todos los escritores del ciclo, y de sistemas lingüísticos que se consideran perezosos o demagógicos.

Realismo mágico y barroco (barroquismos) provocan incomodidad y sarcasmo, si no en el público lector, que adopta las aventuras de los héroes de García Márquez o de Fuentes tanto como plebiscita las ficciones de Cortázar, sí en el ánimo de ciertos escritores y de ciertos críticos que se perciben como vanguardias ${ }^{23}$, por ejemplo, los que animan, a partir del mismo año 1969, la revista Los libros (1969-1976). Sus colaboradores (Beatriz Sarlo, Ricardo Piglia, Nicolás Rosa, Josefina Ludmer, Eliseo Verón, Oscar Massotta, Aníbal Ford, Jorge Rivera, Germán García, entre otros) trabajan a partir de la teoría literaria y de las ciencias humanas; la revista tiene un papel importante en la defensa de una escritura y una crítica no conformistas. El primer editorial, de julio de 1969, dice: "Los libros no es una revista literaria. Entre otras cosas, porque condena la literatura en el papel de ilusionista que tantas veces se le asignara. La revista habla del libro, y la crítica que se propone está destinada a desacralizarlo, a destruir su imagen de verdad revelada, de perfección ahistórica" $(1,3)$.

Justamente, para tener una idea más completa de las poéticas originales que emergían a la par del boom o con su reflujo y que no dejaron de influir de manera duradera en el imaginario de la crítica argentina, hay que tomar también en cuenta los proyectos de artistas que fundarán o participarán en revistas que defienden una idea desacralizadora de la literatura y que se sitúan, declaradamente o no, en las antípodas estéticas de la narración latinoamericana del momento. Uno de ellos es precisamente Lamborghini, revalorizado años más tarde por el trabajo de exhumación crítica de César Aira, que firma en $1969 \mathrm{El} \mathrm{fiord,} \mathrm{un} \mathrm{relato} \mathrm{transgresivo} \mathrm{y} \mathrm{sádico} \mathrm{donde} \mathrm{se} \mathrm{alude} \mathrm{al} \mathrm{peronismo} \mathrm{con} \mathrm{una}$ lengua desaforada. En Lamborghini, que resistirá al formato de la novela y escribirá textos híbridos y "pavorosos" (Bolaño), se da una verdadera impugnación de lo literario, que cuestiona las convenciones de la estética y decreta la obsolescencia de la idea de literatura. Otro escritor de culto, cuya herencia reclaman aun hoy autores en apariencia tan lejanos de su estilo como Alan Pauls o Martín Kohan, es Héctor Libertella, que publica en 1968 El camino de los hiperbóreos y en 1975 Personas en pose de combate, textos de intensa exploración formal, además de un original volumen sobre Nueva escritura en Latinoamérica en 1977. Las poéticas de Lamborghini y de otros autores neo-vanguardistas como Luis Gusmán, Libertella o Ricardo Zelarayán recorren más o menos subterráneamente la primera mitad de la década del 70 . 
20 Estos escritores, influidos por la lectura de Lacan (según Massotta) y de Marx (según Althusser), y afiliados a un saber psicoanalítico que es una de las marcas fuertes de la cultura porteña de la época e irradia centralmente sus literaturas ${ }^{24}$, se reúnen a partir de 1973 en la revista Literal, tribuna de avanzada que considera oportunista toda intención testimonial o declaradamente realista. Literal protesta contra la supuesta transparencia del lenguaje y contra la supresión de su ambigüedad. Sus miembros se afilian a la tradición de escrituras herméticas y de figuras de autor secretas o diletantes que recorre subterráneamente la literatura argentina antes y después de Macedonio Fernández. No es extraño entonces que algunos libros que por esos años provocan escándalo persigan precisamente la descalificación de la transparencia narrativa. Es en parte el caso del ya mencionado Nanina (1968), de Germán García, y sobre todo de El frasquito (1973), de Luis Gusmán, que emplea un estilo de mezcla entre lo culto y lo popular, aunque elaborado en términos semi-cifrados que algunos consideran como neobarrocos ${ }^{25}$. El frasquito lleva un prólogo de Ricardo Piglia, otro escritor que dará que hablar en la década siguiente, situándose, como Saer, pero por diferentes razones, en las antípodas de la herencia de los autores del boom latinoamericano.

21 Parece claro que, aun cuando Buenos Aires fue precisamente uno de los centros más activos de impulso editorial de los autores que formaban parte de la nueva narrativa latinoamericana de los sesenta, las reticencias tempranas en las que he insistido aquí tienen que ver tanto con tradiciones literarias locales como con los esfuerzos por hacer emerger nuevas estéticas a fines de los 60 y en los 70. Obedecen a razones de poética y estética, a posicionamientos ante el mercado y los medios de comunicación de masas, a la necesidad de vincular política y lenguajes artísticos que es propia de la cultura porteña de ese período, y a la existencia de programas neo-vanguardistas que propenden a un uso radical del lenguaje, un deseo que se atenúa pero no cesa con el fin de la década, y que recorre los imaginarios de crítica y creadores hasta hoy.

\section{Pasión crítica}

\section{a. Pedagogía, historia y latinoamericanismo}

22 Los dos tomos de Nueva novela latinoamericana corresponden a un ambicioso proyecto editorial, originariamente concebido en seis volúmenes, que aspiraba sin duda a una presencia fuerte en el panorama de la crítica $\operatorname{argentina}^{26}$. ¿Qué idea de la literatura someten al lector? ¿En qué innovan? ¿Qué estatuto del discurso crítico defienden? ¿Cómo se los recibe?

Desde el título, el adjetivo "nueva" expone la pretensión de estar al diapasón de los tiempos. Se trata de escuchar el Zeitgeist y de intervenir en el presente, de traducir los lenguajes que se están imponiendo, de hacerse eco de lo que (re)suena. Lo "nuevo", como ya se ha señalado a menudo, es por cierto la creencia mayor de aquella época creadora de la esperanza extraordinaria de un "Hombre Nuevo"; es el impulso optimista que sobredetermina paradigmas y discursos, conceptos y valoraciones, y que supera ampliamente las fronteras de la cultura argentina ${ }^{27}$. Los dos prólogos de Jorge Lafforgue muestran sin embargo la dificultad de definir lo nuevo. Ambos se escapan rápidamente hacia la historia y los catálogos, aunque reclaman el mérito de abocarse a lo estrictamente contemporáneo, una idea que aparece subrayada en el subtítulo del segundo volumen ( $L a$ narrativa argentina actual). Si en el título general esta calidad está referida a la narrativa, y 
si el plan mismo de la obra sugiere bien que es la literatura la que está en el centro del debate, el proyecto parece sin embargo inseparable del objetivo de amarrar lecturas inéditas al corpus de prestigio creciente de la literatura hispanoamericana, así como de reunir un grupo de interpretaciones exigentes sobre la literatura argentina. Corpus argentino y corpus latinoamericano, separados de hecho en tomos distintos, quedan al mismo tiempo vinculados bajo ese título que corona la pertinencia reclamada de lo nuevo. La construcción de los volúmenes muestra un propósito pedagógico, a la vez abarcador y selectivo en cuanto al corpus, un criterio ecléctico en materia de discursos críticos y modelos teóricos, y una voluntad de afirmación latinoamericanista, reflejo por otra parte común a los intelectuales de los sesenta y los setenta. Ese enfoque claramente didáctico recorrido por una fuerte inflexión historicista es visible en los dos prólogos del compilador: "La nueva novela latinoamericana" $(1,13-29)$ y "La narrativa argentina actual" (2, 11-29); la intención es que tales páginas sirvan como marco actualizado a un panorama de aquellas formas de escritura que cuentan en lo que va del siglo. Se trata de un material elocuente sobre objetivos y líneas conceptuales, donde se puede observar que Lafforgue concibe el proceso renovador como un impulso orgánico de la historia literaria. Para subrayarlo, vuelve a situar los textos en el tiempo, dando listas de libros, de movimientos, de escuelas, de períodos, y apelando al corte generacional hasta englobar finalmente en la "nueva novela latinoamericana" las obras de los escritores nacidos desde 1915 en adelante $^{28}$. La estrategia es semejante en el prefacio al segundo tomo, que identifica en la historia de la literatura argentina tramos de modernidad a partir de los años 30 e intenta, con más insistencia aun que el primero, una periodización deudora sobre todo del modelo de generaciones -lo que no impide que ese mismo modelo resulte duramente criticado en una nota del mismo prefacio (2, n. 5)-. Aunque en tanto buen conocedor del circuito editorial, Lafforgue se hace cargo del papel del mercado y de las "materialidades" del proceso cultural, los límites de su lenguaje exegético son visibles en su laboriosa definición del trabajo crítico o de la obra de creación $(1,17)$, y en la falta de metodología disciplinaria para abordar la conexión entre sociología y literatura, que sin embargo él mismo postula $(2,24-25)^{29}$. En esos casos suele acudir a fórmulas, bastante socorridas en esos días, sobre una tarea de interpretación capaz de iluminar "la totalidad del proceso histórico de América Latina", o capaz de "emprender el camino de la liberación", sobre una literatura latinoamericana que ha alcanzado el nivel de la literatura occidental $(2,11,14,29)$, etc. Esas fórmulas atraen en cambio la atención sobre la autonomía que se quiere atribuir al conjunto de escrituras latinoamericanas con respecto a los modelos prestigiosos de la tradición occidental.

La decisión de difundir y el deseo de historiar se mezclan estrechamente en la empresa, casi como si su cometido, al borde de lo imposible, fuera el de producir una historia de lo actual, es decir de lo que el presente (corte en el tiempo de la tradición cultural y de la política) y la actualidad (corte en el tiempo del mercado) plantean como desafíos y seductoras urgencias. Tal decisión está también emparentada con otros elementos contextuales. En lo hispanoamericano, parece responder a la aparición de algunos libros e intervenciones unipersonales que intentaban analizar el fenómeno de la nueva narrativa (firmadas, entre 1963 y 1967, por Carlos Fuentes, Luis Harss, Juan Loveluck, E. Rodríguez Monegal) ${ }^{30}$. En el plano de la literatura argentina, se ve estimulada sin duda por una producción disciplinaria que en esos años sesenta se situaba de pronto al alcance del público, en particular a través de la serie de fascículos y libros de Capítulo, la Historia de la literatura argentina ${ }^{31}$. Los tomos de Nueva novela... tienen en común con esta última, que es 
en cambio una verdadera historia literaria por entregas y alcanza por cierto objetivos más amplios y más didácticos, el intento de renovación del lenguaje analítico a través del llamado a nuevas promociones de críticos y la búsqueda de actualización de las fuentes y corpus bibliográficos. Lafforgue mismo, que se refiere a su proyecto como a una obra grupal ya en el primero de sus prólogos (28), lo considera por fin cercano a experiencias colectivas como la de Capítulo (2005: 67 y 68).

Los estudios del primer volumen, dedicados a escritores del continente, traducen como línea dominante la voluntad de presentar trabajos sobre novelas recientes, según el compromiso anunciado, y se ocupan en su mayor parte de obras publicadas dentro del marco temporal de los sesenta, más exactamente entre 1963 y $1968^{32}$. Pero el tomo incluye además ensayos sobre algunas obras notables publicadas en los cuarenta y los cincuenta. Es el caso de los artículos sobre Al filo del agua (1947), El llano en llamas y Pedro Páramo (1953 y 1955), y Los ríos profundos (1958). Es evidente que la compilación no buscaba entonces limitarse al marco de los escritores directamente vinculados con el boom ${ }^{33}$, sino ampliar con nuevas exégesis también la recepción de autores que en principio escapaban a su órbita ${ }^{34}$. En relación con éstos es útil recordar una vez más la escasez, o en el mejor de los casos, la lentitud de difusión de la literatura latinoamericana por aquellos años, excepción hecha de ciertas novelas, dentro de los mismos países del continente, además de la rareza de lecturas especializadas de fácil acceso. En una de sus minuciosas notas al libro (37) Lafforgue recuerda este problema de circulación de ediciones cuando cita el caso de los cuentos de Arguedas, accesibles en Argentina recién en 1967, gracias en parte a una casa montevideana (Arca).

¿Cuál es el estatuto y el carácter de la crítica que el libro defiende? Es indudable que el volumen no puede pretender aspirar a una coherencia programática. A partir de un montaje que aspira a cierta unidad de intención, no evita por lo tanto las características de la obra colectiva o antológica, en la que un grupo heterogéneo de críticos escribe pequeños ensayos que corresponden a miradas, propósitos, aparatos analíticos diferentes, aunque supuestamente vinculados por una identidad de objetivos y percepciones de la literatura. Entre Vargas Llosa escribiendo sobre Arguedas y Josefina Ludmer sobre Vicente Leñero, para no tomar más que un ejemplo, media por cierto la distancia relativamente insalvable que separa el enfoque ensayístico del escritor que trabaja con vehemencia sobre su propia tradición del esfuerzo metódico estricto del universitario, atenido a cierto ascetismo de demostración. El grupo de críticos incluye figuras de escritores en ascenso como Vargas Llosa junto a otras de intelectuales de trayectoria americanista como Ángel Rama y un buen número de críticos argentinos jóvenes egresados de la Universidad de Buenos Aires. Su horizonte generacional tampoco es homogéneo, pero la mayor parte de ellos, (exceptuados Blanco Aguinaga, Ángel Rama y Ernesto Volkening) pertenece a las nuevas promociones de los que en ese momento tienen poco menos o poco más de treinta años y sus trabajos apuntan todos, con mayor o menor éxito, a producir lecturas que superen las perspectivas fenomenológicas. En este plano, el grado más sistemático de aplicación conceptual lo marcan probablemente los artículos de Eduardo Romano sobre Yáñez y de Luis Gregorich sobre Cabrera Infante, con estrategias textuales basadas respectivamente en la antropología y la lingüística estructural, así como, dentro de un marco sartreano, el del mismo Lafforgue sobre Vargas Llosa $^{35}$. El objetivo pedagógico de la empresa queda manifiesto igualmente en las notas del compilador a ciertos autores y ensayos. Al pie de los trabajos sobre Arguedas, Rulfo, Lezama Lima, García Márquez, García Ponce y Vargas Llosa, Lafforgue anota con su 
habitual prolijidad datos sobre el corpus y referencias bibliográficas esenciales, e incluso llega a defender con su propio elogio los nombres de algunos de los críticos (C. Blanco Aguinaga y Ernesto Volkening), cuando éstos son posibles desconocidos en el ámbito argentino.

Nueva novela latinoamericana 2 propone una estructura antológica semejante, con once contribuciones críticas, seguidas ahora por una semblanza de Arlt debida a Juan Carlos Onetti ${ }^{36}$. Como en el primer tomo, ciertos autores pertenecen a promociones ya alejadas en el tiempo; su actualidad, reclamada desde el título, no depende de la fecha de edición de sus primeros libros. Me refiero a Macedonio Fernández, Marechal, Borges, Bioy Casares, Sabato y Arlt, es decir a más de la mitad de los escritores de los que se ocupa el volumen. De modo que aquella actualidad, aquella novedad deben entenderse como conceptos donde se enlazan estrechamente la obra y sus lecturas; lo "actual" es más que nunca una categoría que alude a la crítica y depende del punto de vista de ella. Se declaran actuales autores que se reevalúan o sobre los que se aportan nuevas claves ${ }^{37}$.

Los dos ensayos sobre Macedonio Fernández con los que se abre el libro explicitan esa perspectiva. Macedonio, redescubierto sobre todo a partir de las ediciones que su hijo Adolfo de Obieta comienza a publicar en $1966^{38}$, ocupará un lugar nuevo en el panorama de la crítica argentina. Signo a la vez de ese lugar presente-futuro que se quiere definir y del prestigio que se acuerda a sus textos, los ensayos de Nueva novela... se confían a Noé Jitrik y a Ana María Barrenechea, especialista indiscutida de Borges y de Cortázar, crítica de reconocido rigor metodológico. Jitrik y Barrenechea representan a los críticos veteranos (entre los que habría que incluir a Fernández Moreno), en franca inferioridad numérica frente a todos los demás, que tienen entre veintinueve y treinta y ocho años en el momento de la aparición del libro. En cuanto a Marechal, de quien se analiza Adán Buenosayres, su ejemplo es todavía, si cabe, más significativo. La novela data de 1948, pero después de un largo período de olvido de la obra y de purgatorio del autor, Sudamericana la reedita dos veces en 1966. Marechal ha comenzado a salir de la sombra a causa de su segunda novela, El banquete de Severo Arcángelo, publicada con éxito de lectores en 1965, así como de la progresiva reinserción ideológica del peronismo, que lo asume como su escritor paradigmático, y de sus posiciones tercermundistas bien conocidas que lo llevan incluso a participar en 1967 en el jurado de Casa de las Américas. En 1969, por lo tanto, a un año de su muerte, su nombre se impone junto con el de su novela magistral.

Borges, Bioy y Sabato, los nombres canónicos de la literatura argentina que figuran a continuación en el tomo, aparecen como autores de obras fundamentales sobre las que se intentan investigaciones inéditas. Sea investigaciones originales y autónomas, como la de Nicolás Rosa (ahora incorporado al proyecto de Lafforgue) en torno a la ficción borgiana, o ambiciosas en la descripción de los materiales culturales que cristalizan en la literatura, como la de Jorge Rivera sobre Bioy y la narrativa del 40, o portadoras de planteos poco frecuentes, como la de César Fernández Moreno, que se puede emparentar vagamente con un estudio de recepción. En el mismo orden de ideas hay que ubicar la semblanza sobre Arlt, una página de Onetti que había sido concebida como prólogo a la edición italiana de una de sus novelas, y que de no mediar demoras, hubiera debido, según el compilador, abrir el volumen. El ejemplo informa por supuesto sobre la tendencia del momento a revisar la tradición crítica sobre Arlt así como a la puesta en valor de la escritura de Onetti, pero confirma también la perspectiva historiográfica de Lafforgue, que no quiere presentar su libro sin abarcar a Arlt, a quien considera, junto con Onetti precisamente, como iniciador(es) de la "actual narrativa rioplatense". Y afirma: "me sobrarían los dedos 
de la mano si buscase figuras equiparables a ellos dos en estas latitudes de América latina" (2, 363-365).

31 Entre esas figuras históricas y los más nuevos se ubica Julio Cortázar, al que se refiere el ensayo seminal de A.M. Barrenechea sobre Rayuela. Pero el de Cortázar era a su vez un caso diferente, porque si bien se lo podía vincular por su fecha de nacimiento con algunos de los autores anteriores, su literatura se percibía como claramente moderna y notablemente innovadora y su recepción crítica era favorable tanto entre los que lo asociaban al boom latinoamericano como entre los que lo estudiaban, con nuevos marcos teóricos como lo hace Barrenechea, dentro de la tradición argentina de creación especulativa.

En la otra cabecera del puente tendido por Cortázar aparecen entonces autores que han comenzado a publicar ya en los cincuenta, pero cuyas poéticas implicarían una apertura futura. Son Di Benedetto, Walsh y Conti, todos nacidos en los años veinte. Si la escritura de Di Benedetto no se podría incluir hoy en la categoría de las estéticas abiertas al cambio, y si la trayectoria interrumpida de Conti muestra mayormente una narrativa volcada hacia tonos líricos y meditativos, la inclusión de Walsh, dada su intervención en el discurso de los géneros a la vez que en la relación entre la escritura y la política, se justifica ahora tanto como se justificaba antes. Por eso su presencia está directamente ligada con la tensión que mantiene al proyecto de Lafforgue en fase con el carácter de esos tiempos, la idea de que las luchas políticas argentinas y latinoamericanas se desarrollan a la par en la sociedad y en la cultura, la convicción de que una vanguardia estética es necesariamente productora de una escritura "no alienada" (320).

Manuel Puig es el último de la serie. Lo separan unos veinte años de Cortázar, y a pesar de la marca de contemporaneidad que este último ha impreso en la escritura argentina, ya en el 69 parece evidente que Puig anuncia (administra) una modernidad diferente de todo el resto. Ricardo Piglia, por entonces autor novel, director de colecciones y ya brillante crítico, firma aquí el ensayo dedicado a La traición de Rita Hayworth; su inclusión es prueba del espacio que esa primera novela ha procurado inmediatamente a su autor. Otra prueba se encuentra en las respuestas de un grupo de escritores a una encuesta preparada por Los libros pocos meses más tarde (7, enero de 1970, 10-22). A la pregunta sobre la mejor obra de ficción publicada en la Argentina en 1969, cinco escritores (Beatriz Guido, E. Gudiño Kieffer, Germán García, Osvaldo Lamborghini, Martha Lynch) sobre nueve citan Boquitas pintadas, la segunda novela de Puig. M. Lynch dice con intuición: "es el único escritor importante que ha aparecido en los últimos años. Estoy segura de que su obra futura me dará la razón" (22).

Una vez más, el grupo de críticos reunido en torno a la "nueva novela", vista ahora del lado argentino, propone sensibilidades y estrategias de análisis diferentes. Éstas van desde los intentos de aggiornamento de la crítica textualista inspirada en Tel Quel que practica Noé Jitrik hasta consideraciones de factura periodística sobre las razones de la (buena) reputación de un autor (Fernández Moreno sobre Sabato). Van desde las interpretaciones auténticamente estructuralistas como las de Barrenechea hasta las lecturas de escritor como la de Piglia, que traducen ángulos de ataque y preocupaciones técnicas propias. Van desde una aplicación de modelos antropológicos totalmente coherentes con el corpus que tratan, como el ensayo de Rivera sobre lo arquetípico en la narrativa de Bioy o el de Romano sobre lo mítico en Conti, hasta las exégesis inspiradas a la vez por lo ideológico y lo formal genérico, como la de Aníbal Ford sobre Walsh ${ }^{39}$. Van desde el intento de aplicación de modelos "duros" de crítica interna (Propp, Greimas) 
cuyos resultados contradicen tanto las expectativas de los críticos como las posiciones explícitas del autor, en el artículo de grupo sobre Marechal, hasta un ensayo de crítica semiológica sobre la circulación del sentido entre formas, sintaxis y símbolos textuales (Rosa midiendo armas con los laberintos de Borges) ${ }^{40}$.

Si se lo compara con el tomo 1, el conjunto de los trabajos plantea una relación más sostenida y más firme con los modelos y con la teoría, que sus autores leen con toda la diversidad propia a la época y asumiendo a veces explícitamente las consecuencias de la tensión entre aquellos y el pensamiento político latinoamericanista. El cruce polémico entre los modelos estructuralistas (antropológicos, retóricos, filosóficos) y la búsqueda de significados ligados a los procesos políticos se puede ver en varios de los ensayos (los de Jitrik, del Centro Buenosayres ${ }^{41}$, de Rosa, de Romano); la vinculación programática entre la serie social y la serie literaria en otros (los de Rivera, de Ford, de Piglia). La mirada de estos críticos es doble sin ser estrábica. Se dirige a la vez a proponer otras modelizaciones del canon y a plantear sentidos nuevos, pretende asumir las luchas sociales del presente sin olvidar el carácter ambivalente de la cultura literaria, dependiente de la lógica "traicionera" (Piglia) del lenguaje. Militan por "la desacralización del hecho literario en todos sus planos" (Ford sobre Walsh, 317) ${ }^{42}$, pero se muestran conscientes de la necesidad de renovar los discursos especializados. Tienen una voluntad afirmada de pensamiento sistemático que no es aquí una excepción sino una regla, pero piensan la literatura como una producción interdiscursiva cuya lectura "deja siempre elementos residuales que no alcanza a absorber" (Rosa, 173). A todas esas características no es sin duda ajena la presencia entre ellos de varios autores que intervienen regularmente en Los libros (Sarlo, Núñez, Rosa, Rivera, Ford, Romano, Piglia) ${ }^{43}$.

\section{b. Modernizar la crítica}

En su recuento bio-bibliográfico de 2005, Lafforgue menciona la recepción exitosa que mereció Nueva novela latinoamericana. Los dos tomos "habían circulado muy bien por todo el continente" y habían contado con "varias ediciones" (Cartografía, 62). Es posible que el criterio historicista del compilador y su ecumenismo ${ }^{44}$ en materia de lenguajes críticos, junto con el indudable interés de unos libros que se ocupaban de lo "nuevo" a la vez que ponían en escena nombres prestigiosos, hayan contribuido a suscitar esa buena acogida de especialistas y editores. Ya en el prólogo a su primer volumen el compilador defendía la heterogeneidad de estilos críticos poniéndola bajo el signo de una vocación común:

Nos hallamos ante una obra colectiva. Esto no supone identidad de puntos de vista; pero sí una actitud crítica compartida. Creo que las divergencias de quienes colaboramos en este volumen son sólo parciales, por distintos que sean los métodos de análisis que hayamos utilizado en nuestros trabajos y aun cuando difieran nuestras interpretaciones valorativas. ¿Acaso no pensamos todos que la verdadera literatura -en ella incluidas las más diversas clases de "ensayos"- es una indagación que no se agota en sí misma, que no se resigna a los escalafones del prestigio y del orden, que excluye el acuerdo con el sistema? Porque, en definitiva, la literatura es crítica o nada $(1,28-29)$.

No todos se contentan sin embargo con las buenas intenciones de "una actitud crítica compartida"; del lado argentino, la hora no es propicia a la gran confraternidad de todos los que escriben sobre literatura. Por el contrario, el momento está marcado por un deseo de discriminar y de elegir poéticas, de afilar los instrumentos críticos, de pensar nuevamente el campo literario a la luz de las transformaciones actuales de la cultura y de 
la política, un deseo que protagonizan en primer término las promociones recientes de egresados universitarios que cuentan ya entre sus filas varias voces críticas notorias. La historia de la recepción Nueva novela... ofrece por este motivo una pequeña radiografía de las tensiones que recorren el campo en los mismos años y en los siguientes.

La revista Los libros por ejemplo reacciona prontamente a la aparición de ambos volúmenes. En su reseña al primero, Nicolás Rosa desplaza el punto de mira del corpus previsto de la "nueva novela" a la pregunta por la supuesta pretensión a fundar una "nueva crítica", y concluye lógicamente que una obra heteróclita como la que Lafforgue presenta no puede aspirar a un programa aceptable en ese terreno (Rosa 1969). Discute así su valor exegético, tanto desde el punto de vista de su papel en una incipiente tradición crítica argentina como desde el ángulo de la pertinencia de lenguaje y método necesarios a una nueva crítica. En esa larga reseña aparecen ya dos pautas que caracterizarán muchas de sus páginas ensayísticas, la exigencia de un pensamiento interpretativo sistemático y el ordenamiento de nombres de críticos en grupos o listas que contienen una sanción clasificatoria: los "valiosos", los "rescatables", los "prescindibles". Este esquema lo lleva a distinguir algunos nombres entre los colaboradores y algunos logros, puntuales o no, con una visión muy precisa de sus posiciones frente a la literatura; el futuro probará que su selección era acertada. El artículo se proyecta sin embargo sobre una ambición mayor, que Rosa irá desarrollando en textos posteriores, la de definir la verdadera tarea crítica y la de establecer los parámetros dentro de los que ésta se mueve o podría moverse en la Argentina, lo que la crítica "debería ser". El postulado contiene en su primera parte un impulso normativo que se expresa aquí por la negativa: habría que desembarazar a la crítica de sus mitos, a saber, la supuesta unidad de la obra, su autonomía, la idea de tematización, el prurito esencialista, la creencia en la transparencia del lenguaje. La segunda parte de la idea se expresa en los propios textos de Rosa bajo la forma de las familias de críticos que construirá con gran solvencia y ahínco ordenándolos según estrictos perfiles epistemológicos.

Tres años después, en el prólogo a su segundo volumen, Lafforgue parece querer integrar la lección y anticipar el golpe mostrándose más alerta y combativo ${ }^{45}$ :

La variedad de presupuestos teóricos y de enfoques metodológicos implícita (o explícita) en estos trabajos, si bien pone al descubierto una acentuada desorientación en cuanto a los caminos que debe transitar (o construir) la crítica literaria en Latinoamérica, refleja al mismo tiempo su estado actual en esta región del continente. Porque el presente volumen, de igual modo, junto a, o mejor aun que el anterior, se proyectó como un espacio abierto a las manifestaciones menos esclerosadas y más estimulantes (o renovadoras) de la crítica literaria nacional en todos sus aspectos, desde derivaciones del comentario periodístico hasta aplicaciones del último instrumental europeo en el ámbito local, desde búsquedas tenazmente descriptivas hasta claros encuadres ideológicos (2, 28-29).

Pero esas líneas traslucen también algo menos coyuntural, la permanencia de la idea de que la literatura que se está publicando en el continente muestra un grado de madurez superior al de la crítica, la cual aparece en situación de "acentuada desorientación en cuanto a los caminos que debe transitar (o construir)". Se está hablando aquí de literatura continental, puesto que la literatura argentina absolutamente coetánea no parece estar, tampoco ella, al nivel de lo que muestra la eclosión de la latinoamericana ${ }^{46}$, un sentimiento difuso pero constante en ciertas lecturas de la época. Hay en consecuencia en el segundo prefacio de Lafforgue una suerte de insatisfacción manifiesta por lo hecho por la crítica hasta entonces que no parece un mero alegato pro domo, pero que además 
contiene, encubierta, una valoración tibia sobre la producción literaria argentina reciente. Sus palabras finales son perentorias: la crítica literaria en nuestro país sería una "casi inexistencia" de larga historia (28), "entre nosotros el trabajo crítico dista de haber alcanzado el vigor y la plenitud que exhibe la novela latinoamericana actual" (29).

41 Es probable también que Jorge Panesi, al escribir su valioso estudio sobre Los libros en 1985, haya pensado una vez más en el desafío a la crítica que Rosa planteaba ya en el plano de la autonomía y la madurez de los lenguajes en 1969. En todo caso, mencionando al pasar el libro de Lafforgue, Panesi declara el carácter ancilar del proyecto e insiste en su propia lectura: es con Los libros que aparece el "nuevo ideal" de una escritura "integradora" (del afán de rigor y de militancia) y no con "una crítica que nacía cumpliendo tareas de dama de compañía para la triunfante nueva novela latinoamericana" (2000: 28. Subrayado mío). En esto no disiente, en el fondo, de lo que las palabras del propio compilador sugerían en las líneas citadas ${ }^{47}$.

Cuando Rosa vuelve a mencionar la obra de Lafforgue en un ensayo suyo, ésta es ya un objeto lejano en el tiempo. Estamos en los noventa y se intenta un balance de la cultura argentina en democracia; han pasado casi veinticinco años desde que en 1969 él mismo había respondido a la pregunta sobre la existencia de una nueva crítica por la negativa. En ese artículo de 1993, donde propone una nueva síntesis de veinte años de crítica literaria argentina, no olvida mencionar la heteróclita Nueva novela latinoamericana, a la que atribuye ahora el calificativo de "museo de la crítica" (1993:167) ${ }^{48}$. La ironía suscribe, a pesar de todo, a la idea de que el libro ha entrado a los anales de la tradición. Porque sus lecturas críticas se reconocen como pioneras, Rosa extrae de la serie los nombres que le interesan, visualizando en sus páginas "las primeras operaciones de los críticos que entendemos ocupan hoy una presencia manifiesta y reconocida" (1999: 326). Es decir, en su propio recuento, los pasos iniciales de Sarlo, Romano, Ludmer, Rivera, Piglia, Ford, Rosa mismo, cuyas biografías intelectuales detalla a continuación, pilares de un canon y de una historia que él sigue construyendo infatigablemente ${ }^{49}$.

Los volúmenes de Lafforgue carecen ciertamente de la búsqueda de coherencia que caracteriza a ciertas empresas críticas posteriores donde un grupo de intelectuales que comparte posiciones y prácticas afines se propone intervenir en la cultura con un discurso propio -desde Los libros en los primeros setenta hasta Babel a fines de los ochenta, pasando por Literal, Sitio y Punto de Vista (que desbordará ampliamente el marco cronológico de las anteriores)-. Tampoco proponen mayoritariamente un diagnóstico cultural definido ni sostienen un concepto dominante enfocado sobre la interacción entre sistemas, como por ejemplo lo hacen ya por los mismos años de Nueva novela... 2, los críticos de Los libros (la crítica como "producción"). Logran algunas páginas de gran lucidez analítica, pero no conciben aun la crítica como una práctica que, de vuelta de toda travesía teórica, sea capaz de responder al simulacro de la literatura con su propio simulacro (su propia metáfora), como lo preconizan ciertos brillantes trabajos de Nicolás Rosa. Todavía no están en su propio futuro esos protagonistas de Nueva novela... . Hacia un tiempo no tan lejano, la pasión crítica argentina será indisociable de la obra narrativa de los mejores escritores; los modelos y discursos de las ciencias humanas inspirarán a los artistas más audaces de los ochenta y los noventa; la crítica, la teoría y la ficción se entrelazarán cada vez más estrechamente en las textualidades literarias. Entretanto, la convocatoria de Lafforgue habrá intentado un recorrido a tono con la efervescencia cultural de los tiempos. Su llamado apelaba a críticos atentos a la escritura contemporánea y conscientes de la necesidad de modernizar los discursos de la 
interpretación. En general, no se equivocaban en sus propuestas, ni en el plano de la literatura latinoamericana, ni sobre todo en el de la argentina, donde los trabajos alcanzaban el grado más representativo de las ambiciones del lenguaje crítico en un momento de cambio social y político. Vista desde hoy, después de varias décadas de nuevas propuestas de lectura sobre los mismos y sobre otros autores, y de afianzamiento de una pasión crítica que caracteriza sin discusión el desarrollo intelectual argentino, esa summa parece discreta si no modesta, pero hay que reconocerle la obstinación que se les reconoce a los pioneros y la oportunidad que se concede a las piezas patrimoniales. Más que síntoma, muestreo, y más que brote, empresa voluntariosa, los tomos de Nueva novela latinoamericana 1 y 2 enmarcaban un corpus posible de casi nuevos, nuevos y novísimos creadores y críticos a tener en memoria advirtiendo, con su propio ejemplo, sobre la imposibilidad futura de contentarse con lecturas conformistas de la sociedad y de la literatura.

\section{BIBLIOGRAFÍA}

Altamirano, Carlos (1983). “Prólogo”. En: Altamirano, Carlos y Sarlo, Beatriz. Ensayos argentinos. De Sarmiento a la vanguardia. Buenos Aires: Centro Editor de América Latina. Colección Capítulo. Las nuevas propuestas, p. 9-12.

(1994). “Memoria del “69”'. Punto de Vista (Buenos Aires), 49, agosto 1994, p. 5-7.

Bolaño, Roberto (2004). “Osvaldo Lamborghini: mártir”. En: Entre paréntesis. Barcelona:

Anagrama, p. 141-142.

Casa de las Américas, año IV, julio-agosto 1964.

Casa de las Américas, año VIII, 46, enero-febrero 1968.

Casa de las Américas, año IX, 51-52, noviembre 1968-febrero 1969.

Casa de las Américas, año IX, 53, marzo-abril 1969.

Casa de las Américas, año IX, 54, mayo-junio 1969.

Casa de las Américas, año XI, 61, julio-agosto 1970.

Cabrera Infante, Guillermo (1968). “Las fuentes de la narración.” (Entrevista de Emir Rodríguez Monegal). Mundo Nuevo, 25, Julio 1968, p. 41-58.

Carpentier, Alejo (1979). "La novela latinoamericana en vísperas de un nuevo siglo”. En: Tientos, diferencias y otros ensayos. Barcelona: Plaza y Janés, 1987, p. 141-158.

Cella, Susana (1999). "Panorama de la crítica”. En: Cella, Susana (dir. volumen). La irrupción de la crítica. En: Jitrik, Noé (dir.). Historia crítica de la literatura argentina. Buenos Aires: Emecé. Vol. 10, p. 33-62.

Chitarroni, Luis (2000). "Continuidad de las partes, relato de los límites”. En: Drucaroff, Elsa (dir. volumen). La narración gana la partida. En: Jitrik, Noé (dir.). Historia crítica de la literatura argentina. Buenos Aires: Emecé. Vol. 11, p. 161-182. 
Dalmaroni, Miguel (2005). "Historia literaria y corpus crítico (aproximaciones williamsianas y un caso argentino)". Boletín del Centro de Estudios de Teoría y Crítica Literaria (Rosario), 12, diciembre 2005. www.celarg.org

De Diego, José Luis (2004). Quién de nosotros escribirá el Facundo. Intelectuales y escritores en Argentina (1970-1986). La Plata: Ediciones Al Margen.

Donoso, José (1972). Historia personal del boom. Barcelona: Anagrama.

Ford, Aníbal (1969). “El vandorismo”. Los libros, 1, julio de 1969, p. 28-29.

Garramuño, Florencia (2009). La experiencia opaca. Literatura y desencanto. Buenos Aires: Fondo de Cultura Económica.

González, Horacio (2000). "El boom: Rastros de una palabra en la narrativa y la crítica argentina". En: Drucaroff, Elsa (dir. volumen). La narración gana la partida. En: Jitrik, Noé (dir.). Historia crítica de la literatura argentina. Buenos Aires: Emecé. Vol. 11, p. 405-430.

King, John (1986). Sur. A study of the Argentine literary journal and its role in the development of a culture, 1931-1970. Cambridge: Cambridge University Press.

Laddaga, Reinaldo (2007). Espectáculos de realidad. Ensayo sobre la narrativa latinoamericana de las últimas dos décadas. Rosario: Beatriz Viterbo.

Lafforgue, Jorge (comp.) (1969). Nueva Novela latinoamericana 1. Buenos Aires: Paidós.

(1969). "La nueva novela latinoamericana". En: Nueva Novela latinoamericana 1.

Buenos Aires: Paidós, p. 13-29.

(comp.) (1972). Nueva Novela latinoamericana 2. La narrativa argentina actual. Buenos Aires: Paidós.

(1972). “La narrativa argentina actual”. En: Nueva Novela latinoamericana 2. Buenos Aires: Paidós, p. 11-29.

(2005). Cartografía personal. Escritos y escritores de América latina. Buenos Aires:

Taurus.

Link, Daniel (2006). “Tercer Corte (1968-1983). Crisis de la literatura”. En: Leyenda. Literatura argentina: cuatro cortes. Buenos Aires: Entropía, p. 103-121.

Los libros, 1, julio 1969. http://izquierda.library.cornell.edu/i/izquierda/libros.html

Los libros (1969). "La creación de un espacio". 1, julio 1969, p. 3.

Los libros, 2, agosto 1969. http://izquierda.library.cornell.edu/i/izquierda/libros.html Los libros, 3, septiembre 1969. http://izquierda.library.cornell.edu/i/izquierda/libros.html Los libros, 4, octubre 1969. http://izquierda.library.cornell.edu/i/izquierda/libros.html Los libros, 5, noviembre 1969. http://izquierda.library.cornell.edu/i/izquierda/libros.html Los libros, 6, diciembre 1969. http://izquierda.library.cornell.edu/i/izquierda/libros.html Los libros, 7, enero-febrero 1970. http://izquierda.library.cornell.edu/i/izquierda/libros.html Los libros (1970). “La literatura argentina 1969” (Encuesta). 7, enero-febrero 1970, p. 10-12 y 21-22. Los libros, 8, mayo 1970. http://izquierda.library.cornell.edu/i/izquierda/libros.html Los libros (1970). “Etapa”. 8, mayo 1970, p. 3.

Los libros, 9, julio 1970. http://izquierda.library.cornell.edu/i/izquierda/libros.html 
Los libros, 25, marzo 1972. http://izquierda.library.cornell.edu/i/izquierda/libros.html Los libros, 28, septiembre 1972. http://izquierda.library.cornell.edu/i/izquierda/libros.html Los libros (1972). "Hacia la crítica” (Encuesta). 28, septiembre 1972, p. 3-7.

Matamoro, Blas (1969). “Borges y la crítica. Respuesta”. Los libros, 28, septiembre de 1972, p. 19-20.

Mudrovcic, María Eugenia (1999). “El arma periodística y una literatura "necesaria”. El caso Primera Plana”. En: Cella, Susana (dir. volumen). La irrupción de la crítica. En: Jitrik, Noé (dir.). Historia crítica de la literatura argentina. Buenos Aires: Emecé. Vol. 10, p. 295-311.

Mundo Nuevo, 1, Julio 1966.

Mundo Nuevo, 17, Noviembre 1967.

Mundo Nuevo 18, Diciembre de 1967.

Mundo Nuevo, 25, Julio 1968.

Olguín, Sergio y Zeiger, Claudio (1999). "La narrativa como programa. El realismo frente al espejo”. En: Cella, Susana (dir. volumen). La irrupción de la crítica. En: Jitrik, Noé (dir.). Historia crítica de la literatura argentina. Buenos Aires: Emecé. Vol. 10, p. 359-375.

Orecchia, Teresa (1969). "Lafforgue y otros: Nueva novela latinoamericana" (Reseña). Sur (Buenos Aires), 321, noviembre-diciembre de 1969, p. 105-108.

Orecchia Havas, Teresa (2012). "Fiction et construction de traditions littéraires dans le contexte argentin”. En : Moulin Civil, Françoise, Olivier, Florence, Orecchia Havas, Teresa (dir.). La littérature latino-américaine au seuil du XXI siècle. Colloque de Cerisy 2008. Paris/Londes: Aden, p. 345-368.

Panesi, Jorge (2000 [1985]). "La crítica argentina y el discurso de la dependencia”. En: Críticas. Buenos Aires: Norma, p. 17-48.

(2005). “Discusión con varias voces: el cuerpo de la crítica". Boletín del Centro de Estudios de Teoría y Crítica Literaria (Rosario), 12, diciembre 2005. www.celarg.org

También en www.lectorcomun.com

Piglia, Ricardo (2008). “El lugar de Saer”. En: Carrión, Jorge (ed.). El lugar de Piglia. Crítica sin ficción. Barcelona: Candaya, p. 162-188.

Prieto, Adolfo (1983). “Los años sesenta”. Revista Iberoamericana (Pittsburgh), XLIX, 125, OctubreDiciembre de 1983, p. 889-901.

Rama, Ángel (ed.) (1981). Mas allá del boom. Literatura y mercado. México: Marcha.

(1981). “El “boom” en perspectiva”. En: Mas allá del boom. Literatura y mercado. México:

Marcha.

Rama, Ángel (1982). "La narrativa en el conflicto de las culturas”. En: Rouquié, Alain (comp.). Argentina, hoy. México: Siglo XXI, p. 249-279.

Rodríguez Monegal (1967). “Diario de Caracas”. Mundo Nuevo, 17, Noviembre 1967, p. 4-24.

Rosa, Nicolás (1969). “Nueva novela latinoamericana. ¿Nueva crítica?”. Los libros, 1, julio de 1969, p. 6-8.

(1969). “La crítica como metáfora". Los libros, 2, agosto de 1969, p. 4-5.

(1972). “Borges y la crítica”. Los libros, 26, mayo de 1972, p. 19-21. 
(1972). “Borges y la crítica. Contracrítica”. Los libros, 28, septiembre de 1972, p.

21-24.

(1981). “Prólogo”. En: A. Barrenechea, N. Jitrik, J. Rest y otros. La crítica literaria contemporánea. Vol. 1. Buenos Aires: Centro Editor de América Latina, Capítulo, Biblioteca argentina fundamental 113, p. I-VIII. Reproducido como: "La crítica literaria argentina actual. Convergencias/ Divergencias”. En: Los fulgores del simulacro. Rosario: Universidad Nacional del Litoral. Cuadernos de Extensión Universitaria, 1987, p. 79-93.

(1987 [1986]). "Estos textos, estos restos". En: Los fulgores del simulacro. Rosario: Universidad Nacional del Litoral. Cuadernos de Extensión Universitaria, p. 9-18.

(1987). Los fulgores del simulacro. Rosario: Universidad Nacional del Litoral. Cuadernos de Extensión Universitaria.

(1993). "Veinte años después o la "novela familiar" de la crítica literaria". En: La cultura argentina. De la dictadura a la democracia. Cuadernos Hispanoamericanos, 517-519, julioseptiembre 1993, p. 161-186. Reproducido en: Rosa, Nicolás (ed.). Políticas de la crítica. Historia de la crítica literaria en la Argentina. Buenos Aires: Biblos, 1999, p. 321-347.

Sarlo Sabajanes, Beatriz (1972 a). “Novela argentina actual: códigos de lo verosímil”. Los libros, 25, marzo de 1972, p. 18-19.

(1972 b). "La enseñanza de la literatura. Historia de una castración”. Los

libros, 28, septiembre de 1972, p. 8-10.

Schmucler, Héctor (1972). "La búsqueda de la significación literaria”. Los libros 28, septiembre de 1972, p. 17-18.

Sosnowski, Saúl (1981). "Lectura sobre la marcha de una obra en marcha”. En: Rama, Ángel. Mas allá del boom. Literatura y mercado. México: Marcha, p. 191-236.

Terán, Oscar (1991). Nuestros años sesenta. La formación de la nueva izquierda intelectual. Buenos Aires: Puntosur.

\section{NOTAS}

1. Aunque el segundo tomo, Nueva novela latinoamericana 2, aparece en 1972 , las fechas al pie de los artículos que contiene indican que han sido redactados entre 1968 y 1970. Su coexistencia en el plan inicial del compilador, la coetaneidad de su redacción y ciertas características internas comunes hacen que se pueda considerar a ambos volúmenes como las dos partes de un solo proyecto.

2. El caso de Los libros ha sido estudiado por Jorge Panesi (2000 [1985]), quien demuestra cómo la crítica argentina, en tanto discurso autónomo que aspira a ser sistemático, recibe un impulso crucial del encuentro polémico entre la política y la lectura de los modelos teóricos. Ver igualmente el detallado análisis de De Diego (2004) sobre la investigación de Panesi.

3. En tanto proceso literario fue rápidamente declarado exhausto, signo de la labilidad de sus marcos. Sobre este punto litigioso hubo rápidamente algunos balances colectivos, además de los enfoques de autor único, como la Historia personal del boom, de José Donoso (1972). En 1979, la ponencia de Ángel Rama al coloquio de Washington, "El "boom" en perspectiva" (Rama 1981), recuerda que ya hacia 1972 se había comenzado a decretar su extinción. Rama propone, con razón, que los argumentos que celebraban una explosión literaria a mediados de los sesenta eran tan poco sólidos como los que anunciaban su cese 
unos pocos años después. Los escritores continuaban produciendo novelas de la misma calidad, los lectores otorgaban su atención a lo que se publicaba, y sin embargo se dictaminaba un ocaso que coincidía solamente con el declive de rasgos externos, comerciales y de publicidad. La fecha de 1964, arbitraria como otras, es la que elige Rama, a pesar de ciertos reparos; se trata del año en que los libros de Cortázar se reeditan con tirajes aumentados.

4. Primera Plana apareció entre noviembre de 1962 y agosto de 1969, en que fue cerrada por decreto del gobierno. Volvió a aparecer entre 1970 y 1971. Sobre el papel modernizador de la revista ver Terán (1991: 81-95) y Mudrovcic (1999).

5. Y esto a pesar de los intentos de Enrique Pezzoni, secretario de redacción de la revista a partir de 1968, por incluir textos y reseñas de nuevos autores latinoamericanos, un cometido igualmente recordado por King (1986: 184). Ver Orecchia 1969 para la reseña al primer volumen de Lafforgue.

6. El esfuerzo de clarificación de los críticos acaba por apelar siempre a los nombres y a las fechas. Entre los primeros, el de Borges ronda los análisis del boom como una mala sombra, como si fuera necesario o inevitable computarlo entre sus protagonistas, aun contra toda lógica. Saúl Sosnowski, por ejemplo, dice: "Borges supo que ciertos autores crean sus precursores. De este modo, y por derecho propio, deben sumarse [a la lista de primeras figuras del boom] los nombres del mismo Borges junto a Onetti y otros en un abanico que no se cierra con el máximo aporte de Roa Bastos" (Más allá del boom, 191). La lista quedaba significativamente abierta ...

7. Las objeciones que muy pronto se opusieron al boom desde diversos centros se dejan enumerar con facilidad: son críticas a la imitación de modelos extranjeros, a la reducción del corpus latinoamericano a unos pocos ejemplos estelares, a la adscripción de obras de nivel muy diferente, y a la nueva dependencia de las técnicas publicitarias por parte de los editores. Las polémicas sobre el caso no escasearon tampoco entre escritores ya desde el fin de los sesenta. Rama (1981) recuerda las que tuvieron lugar entre José María Arguedas y Cortázar (1968 y 1969), entre Collazos, Cortázar y Vargas Llosa (1969), entre Vargas Llosa y Rama (1971 y 1972). Cortázar, ya implicado en los debates de la izquierda latinoamericana y adentrándose en posiciones que suponían una franca politización de su pensamiento, hace inclinar la balanza hacia la cuestión de la identidad, que según él, es un vector esencial de las nuevas búsquedas del público lector, y en consecuencia, de la nueva situación de la narrativa.

8. La viñeta de Los libros que señala la publicación de Maladrón en 1969, dice: "El premio Nóbel guatemalteco reincide (inútilmente) en su intento de construir una mitología poética latinoamericana" (1, p. 33). (Bastardilla en el original).

9. Para una puntualización acerba y polémica sobre el estado de los estudios de Letras a fines de los sesenta ver el artículo de Beatriz Sarlo (1972 b).

10. El artículo de Adolfo Prieto (1983) presenta una de las mejores síntesis sobre los 60 como años de cruce. Cruce entre los reflejos de una sociedad que se estrenaba en el consumo cultural y nuevos procesos políticos que comenzaban a emerger sin lograr imponerse; cruce entre concepciones experimentales del arte y eclosión de una máquina de promociones comprometida con el mercado; cruce en fin entre un espacio potencialmente abierto a los grandes debates literarios y un abandono de esa posibilidad a las breves polémicas de la nota periodística.

11. Un comentario sobre la percepción distante de las culturas del continente que trasluce una revista como Sur, aun en sus momentos de mayor reconocimiento de la producción latinoamericana, se puede leer en J. King: "Even Sur, however, could not fail to observe the increasing interest in Latin America, especially with the North American 'Alliance for Progress'. 
Within this context, a major attempt to come to terms with Latin American historical development in the 1960s was made in issue $\mathrm{n}^{\circ} 293$ (March-April 1965). (...) The introduction declares Sur's continuing interest in the problems of Latin America, but it is perhaps significant that a journal published in that continent should dedicate a special issue to Latin America in the same way as it would survey Japanese or Canadian literature: in many ways Peru or Bolivia remained more foreign than Japan" (1986: 181-182).

12. Ciertas editoriales pequeñas o medianas que aparecen en los sesenta buscan agilizar el mercado del libro argentino tanto en literatura como en ciencias humanas, como Jorge Álvarez (1963-1967), que publica novedades argentinas y latinoamericanas, o Ediciones de La Flor, que saca Paradiso en 1968, o Galerna, que sucede a Jorge Álvarez en 1967. La acción de editores como Porrúa (Sudamericana), Jorge Álvarez o Daniel Divinsky (La Flor) permite que se expanda, llevada por la agitación local y la onda del boom, la cifra de ventas y la variedad de textos, e inicia la era del marketing librero con las campañas de prensa dedicadas a Cien años de soledad en 1967 (ver entre otros González 2000: 416). Otro dato clave es la publicación de series de libros baratos que buscaban ampliar el conocimiento de la historia de la literatura argentina, como la Serie del Siglo y Medio de la Editorial Universitaria de Buenos Aires (1960: un siglo y medio desde la fecha de la Independencia). El novel Centro Editor de América Latina (Boris Spivacow) impulsó por su parte las colecciones de literatura hispanoamericana reciente, las de literatura argentina, y con un nivel de análisis no practicado por ninguna publicación periódica hasta esa fecha, publicó por entregas dos ambiciosas historias de la literatura argentina (Capítulo) que todavía hoy son estudios enciclopédicos de referencia.

13. La primera Crisis, que se funda en 1973 (número 1 en mayo de ese año, dir. Galeano y Vogelius), se dedica a promover una literatura argentina inserta en un ámbito continental con un discurso abiertamente tercermundista.

14. Por todos estos motivos, la costumbre de los historiadores del boom de ubicar a ciertos autores argentinos o uruguayos como Cortázar u Onetti dentro del marco del fenómeno o en sus zonas-límite, resulta siempre un tanto extraña a los ojos de un lector (un crítico) argentino que piense en términos de poéticas.

15. Una prueba del alcance que podía asumir ese rescate es el libro de Josefina Ludmer, Onetti. Los procesos de construcción del relato (1977). La misma Josefina Ludmer había firmado, cinco años antes, una obstinada lectura estructuralista y psicoanalítica de García Márquez Cien años de soledad: Una interpretación (1972). Evidentemente, estos trabajos, que no comportan la más mínima mención al famoso boom, son una prueba del nivel de exigencia de la crítica argentina a principios de los setenta y muestran cuál era su grado de desarrollo analítico. Informan también sobre una tradición de lectura que no podía satisfacerse con dictámenes exclusivamente sociológicos.

16. No olvidemos tampoco la relectura, a finales de los sesenta, de las novelas surgidas de un regionalismo/indigenismo tardío pero considerado como militante, como El mundo es ancho y ajeno (1941), o de las novelas de la revolución mexicana, que atrajeron el interés de los universitarios a comienzos de los setenta, o el descubrimiento de Alejo Carpentier a través de las ediciones Arca de Montevideo, etc. Todas las sangres, de J. M. Arguedas, fue editada por Losada en 1964, pero su mayor difusión data de principios de los setenta. Son libros que se leen al amparo de la ola de fraternidad tercermundista.

17. Sobre este punto ver por ejemplo las notas bibliográficas de Casa de las Américas del mismo año 69 (sección "Al pie de la letra") y el juicio de John Brushwood citado por Rama (1981: 84).

18. La coincidencia entre vanguardia artística y política, la hegemonía de la izquierda, han sido señaladas igualmente por Beatriz Sarlo: “Cuando se llega a comienzos de la década de 1970, se 
tiene la sensación de que la izquierda ha ganado una batalla cultural que la vuelve muy visible en el campo cultural y en el artístico" (citada por Garramuño 2009: 50).

19. Sigo aquí la argumentación del ensayo de Link, que cita la lengua enloquecida de Pizarnik, el lenguaje punk de Lamborghini, el discurso coloquial de Puig, las entonaciones criollistas de Walsh, Zelarayán o Gusmán.

20. Por ejemplo en la pluma de Oscar Massotta, quien sostiene que los medios tienen un carácter "potencialmente revolucionario" (Conciencia y estructura, citado por Link 2006: 114).

21. Citado por R. Piglia, “El lugar de Saer” (en Carrión 2008: 168).

22. Las dos fechas contienen una dosis de arbitrariedad. Sobre 1964 y las ediciones de Julio Cortázar, ver más arriba, nota 3. 1974 es la fecha de la primera edición de Yo, el Supremo (Roa Bastos).

23. Un ejemplo de esta reacción lo proveen las lecturas de la novela Sagrado (1969), de Tomás Eloy Martínez. Mientras Osvaldo Lamborghini la enjuicia sin piedad en una nota bibliográfica (González 2000: 405), porque se trataría de una escritura artificiosa y epigonal del realismo mágico aplicada a un tema provinciano, una revista como Casa de las Américas la encomia, reproduciendo parte de una nota de Antonio Skármeta y de una entrevista a Martínez (Casa de las Américas, 61, p. 187-188). Los libros, por su parte, confía el libro a Santiago Funes, que firma una reseña deudora de enfoques teóricos poco ajustados a la novela (Los libros, 7, 23-24).

24. Gusmán y García serán psicoanalistas y ensayistas en esa especialidad.

25. Lo que surge como neo-barroco en Gusmán estará emparentado con la estética que se elabora durante los 80 en la poesía de Perlongher, o incluso en la prosa de Néstor Sánchez, que operan con estrategias de inestabilidad textual asociadas a un imaginario de lo marginal.

26. Jorge Lafforgue detalla el plan de la obra en el prólogo al primer volumen. Además de los dos tomos finalmente publicados estaban planeados: uno más sobre literatura latinoamericana ("dedicado a estudiar la novelística de Carpentier, Onetti, Garmendia, Fuentes, Droguett, etc."), dos "de carácter documental" con testimonios de escritores "protagonistas de esta polémica renovación de la literatura latinoamericana" y uno sobre novela brasileña ("La nueva novela latinoamericana", 28). El plan hace visible el predominio de la literatura continental sobre la argentina, aunque no sepamos si los testimonios de escritores incluían a los argentinos entre los latinoamericanos. En 2005, en Cartografía personal, Lafforgue vuelve sobre el tema, pero menciona ahora un proyecto en cuatro volúmenes, sin más detalle (67).

La revista Primera Plana había insertado en su momento una breve columna anónima para anunciar el libro, en la que se lee: “ “A pesar de ser un libro de crítica literaria, no habrá en él complacencia, ni solemnidad, ni academicismo: eso sí, mucho rigor." Tal es la descripción que hace de La nueva novela latinoamericana I, Jorge Lafforgue, el compilador de este trabajo, "el primero no traducido", que en breve lanzará la colección Letras Mayúsculas, de la Editorial Paidós, cuyo regidor es David Viñas. Es posible que este libro colecticio sea el eslabón inicial de un proyecto más amplio: un volumen dedicado a Onetti, Fuentes, Carpentier y Garmendia, otro sobre la moderna narrativa argentina a partir de Macedonio Fernández; un tercero para la novela brasileña; y dos, de olvidados testimonios, documentos, reportajes, manifiestos y polémicas antañonas."(Primera Plana 322, 25 de febrero 1969, p.48.)

27. Referido a la literatura, el adjetivo se disemina en las páginas de Mundo Nuevo tanto como en las de Casa de las Américas ("nueva literatura venezolana", nueva narrativa latinoamericana”, “joven literatura cubana”, etc.), incluso en el recuento de crónicas que 
abordan lo latinoamericano desde los Estados Unidos o Europa (Casa de las Américas, 53, 157-159 y 54, 188-190, etc.). Como en Mundo Nuevo, en Casa ... se publican muchas de las páginas de ficción y de crítica de los autores de la nueva narrativa (ver por ejemplo el número 26, 1964).

28. La amplia guía de narrativa reciente que cierra el primer prólogo, titulada "Catálogo con salvedades" (22-24), va desde el momento de "despegue" del proceso renovador, 1940 ( $\mathrm{La}$ invención de Morel), hasta 1968 (varias obras).

29. El primer volumen lleva además un epígrafe de Sartre que señala un marco moral al trabajo crítico: "Es preciso que volvamos a la modestia y al gusto del riesgo; [...] es preciso que el crítico renuncie a juzgar con seguridad y comparta la suerte de los autores" (Situations, II).

30. Lafforgue indica todos estos antecedentes en una larga nota del prólogo a su primer volumen $(1,26$, nota 2$)$ y vuelve a ellos de manera ampliada y sumamente detallada en el libro-balance de toda su trayectoria, Cartografía personal (2005: 67-88).

31. Capítulo, la Historia de la literatura argentina publicada por el Centro Editor de América Latina (CEAL), colección de fascículos acompañados por un libro en edición de bolsillo, salió semanalmente desde agosto de 1967 hasta septiembre de 1968 en su primera versión (Ver también aquí nota 12). Fue seguida por Capítulo Universal, una nueva colección del mismo sello, a menudo redactada por los mismos especialistas, que incluyó varios números sobre literaturas de América latina, así como, en 1970 y 1971, una serie de panoramas de la crítica (formalismo, estructuralismo, marxismo, etc.). La segunda versión, muy ampliada, de Capítulo argentino salió a partir de 1979.

32. Por orden cronológico, los autores tratados van desde los nacidos antes de la Primera Guerra hasta los nacidos a mediados de los años 30. Por orden de aparición en el tomo: Vargas Llosa escribe sobre Los ríos profundos (1958), de J. M. Arguedas (1911); Eduardo Romano sobre Al filo del agua (1947), de Agustín Yáñez (1904); Carlos Blanco Aguinaga sobre El llano en llamas (1953) y Pedro Páramo (1955), de Rulfo (1918); Josefina Delgado sobre El paredón (1963), La otra mitad (1966) y Con las primeras luces (1966), novelas de Carlos Martínez Moreno (1917); Vargas Llosa sobre Paradiso (1966), de Lezama Lima (1910); E. Volkening sobre Cien años de soledad (1967), de García Márquez (1927); Angel Rama sobre Figura de paja (1964), La casa en la playa (1967) y La presencia lejana (1968), novelas de Juan García Ponce (1932); I. Josefina Ludmer sobre Los albañiles (1963), de Vicente Leñero (1933); J. Lafforgue sobre La ciudad y los perros (1963), de Vargas Llosa (1936); Luis Gregorich sobre Tres tristes tigres (1967), de Cabrera Infante (1929); Nora Dottori sobre José Trigo (1966), de Fernando del Paso (1935).

33. En Cartografía personal, reimprimiendo con correcciones un viejo artículo de 1972, Lafforgue recorre nuevamente, con el mismo detenimiento de ex editor que caracteriza sus intervenciones, datos sobre la cronología y los entretelones del boom (Ver "Narrativa latinoamericana. Una entrada". Lafforgue 2005: 79-88). En particular, retoma el rol de las editoriales y de Primera Plana para establecer la responsabilidad del periodismo en la consagración y posterior rápida devaluación del proceso. Anota bibliografía y fuentes periodísticas que se citan raramente (Ramiro de Casasbellas), indica ciertas palinodias (Rama, Rodríguez Monegal) y muestra bien cuándo empiezan a ser atacados los escritores estrella (Vargas Llosa, García Márquez, Cortázar). El artículo, oportuno para revisar la actitud de los que ensalzaron el fenómeno, informa también sobre la relativa independencia de criterio de Lafforgue en su propia compilación. Tangencialmente, se confirma por otra parte su perspectiva historicista: el boom es para él lo superficial; lo profundo sería ver la literatura latinoamericana en su historia (85-86).

34. La contraportada del libro merece ser citada: "Discutido y discutible, sospechoso, arduo, sin duda apasionante, el boom de la novela latinoamericana constituye el debate del día. Pero este fenómeno, ¿qué encubre? ¿Sólo una campaña publicitaria hábilmente orquestada por algunas revistas y editoriales que se empeñan en vender sus productos? $¿ 0$ se trata realmente de una 
benéfica explosión en el páramo de nuestra literatura: hasta ahora dependiente, sometida, bastarda, repentinamente adulta, vigorosa y sabia?" (Subrayado mío).

35. Respectivamente: "Novela e ideología en Agustín Yáñez" (55-84); “Tres tristes tigres, obra abierta" (241-261); “La ciudad y los perros, novela moral” (209-239).

36. El volumen contiene los trabajos de: Noé Jitrik sobre Museo de la Novela de la Eterna (1967), de Macedonio Fernández (1874); Ana M. Barrenechea sobre el humor en M. Fernández; Hortensia Lemos, Ángel Núñez, Nannina Rivarola, Beatriz Sarlo y Susana Zanetti (Centro de Investigaciones Literarias Buenosayres) sobre Adán Buenosayres (1948), de Leopoldo Marechal (1900); Nicolás Rosa sobre la ficción (1944-1949) de Borges (1899); Jorge Rivera sobre La invención de Morel (1940) y Plan de evasión (1945) de Bioy Casares (1914); C. Fernández Moreno sobre El túnel (1948) y Sobre héroes y tumbas (1961), de Ernesto Sabato (1911); A. M. Barrenechea sobre Rayuela (1963), de Cortázar (1914); Noemí Ulla sobre Zama (1956), de Antonio Di Benedetto (1922); Aníbal Ford sobre la narrativa (1953-1969) de Rodolfo Walsh (1927); E. Romano sobre Sudeste (1962), de Haroldo Conti (1925); Ricardo Piglia sobre La traición de Rita Hayworth (1968), de Manuel Puig (1933); Juan Carlos Onetti sobre R. Arlt (1900).

37. En el prólogo, lamentando la distancia que media entre su proyecto original y lo que se pudo concretar para el segundo volumen, Lafforgue deplora la ausencia de trabajos sobre "Arlt, Cerretani, Mujica Láinez, Pla, Kordon, Viñas, Moyano y Saer" (28).

38. Macedonio protagoniza uno de los casos de recepción más interesantes de la época. Además de las antologías de sus textos que preparan Borges, Adolfo de Obieta y Carlos Mastronardi en 1961, 1964 y 1966 respectivamente, en 1966 comienza la publicación de sus escritos inéditos o semi-inéditos por A. de Obieta en el Centro Editor de América Latina (CEAL), a la que seguirán las ediciones de Corregidor en los primeros setenta, siempre al cuidado de Obieta. Es la época del redescubrimiento crítico y editorial del escritor y de su obra. Germán García publica un libro de entrevistas a testigos titulado Hablan de Macedonio Fernández (Carlos Pérez, 1969), escribe sobre Macedonio en el primer número de Literal (1973), y en 1975 firma La escritura en objeto, un brillante análisis de corte psicoanalítico. A principios de los setenta, la novel revista Crisis redescubrirá a su vez a Macedonio, pero inscribiéndolo en una línea de vanguardia "pobre" y tercermundista.

39. Respectivamente: "La "novela futura" de Macedonio Fernández" (30-70); "El caso Sabato" (205-221); "La estructura de Rayuela, de Julio Cortázar" (222-247); “Clase media; cuerpo y destino ( Una lectura de La traición de Rita Hayworth de Manuel Puig)" (350-362); "Lo arquetípico en la narrativa argentina del 40" (174-204); “Conti: de lo mítico a lo documental" (323-349); “Walsh: la reconstrucción de los hechos" (272-322).

40. Respectivamente: "Pruebas y hazañas de Adán Buenosayres" (89-139); "Borges o la ficción laberíntica" (140-173).

41. El artículo del Centro de Investigaciones Literarias Buenosayres contiene el mejor ejemplo de esta situación. Al cabo de un minucioso examen de la novela más importante de Marechal siguiendo "un modelo de análisis del cuento folklórico", los críticos se ven obligados a concluir que tal examen revela un texto donde los planos de lo social y de lo individual son excluyentes. $Y$ concluyen que el método no les permitió finalmente encarar la oposición entre el pensamiento del autor, afiliado a "un movimiento político nacional y popular", y la ideología universalista y monológica de la obra (137-139). Poco tiempo después el mismo Centro publicó un artículo en el que volvía sobre esta experiencia metodológica (ver Lafforgue 2005: 101).

42. Aníbal Ford firma igualmente la reseña de ¿Quién mató a Rosendo? en el numero 1 de Los libros (1969).

43. Jorge Panesi ha analizado la "incomodidad frente a los modelos" en relación con Los libros. Pienso que así como éste, algunos otros rasgos señalados por él en la práctica de la revista se encuentran igualmente en Nueva Novela 2, aunque no como "axiomas", sino como principios que recorren en mayor o menor grado el volumen porque son dominantes en la cultura argentina de 
la época, en particular la vinculación entre la lucha cultural y la lucha política (ax. 1) y el latinoamericanismo (ax. 2) (2000 [1985]). Para un trabajo de gran inteligencia en relación con la adopción y la adaptación de modelos epistemológicos, ver el breve artículo de Altamirano 1983.

44. El ecumenismo de Lafforgue es útil para su propósito antológico, pero resulta quizás enemigo de una perspectiva más sistemática. En todo caso, es uno de los pocos que defienden tanto a los críticos universitarios como a las páginas del periodismo especializado, actitud que se volvió realmente excepcional en las décadas siguientes, en las que ni la crítica de los periódicos ni la de la "Academia" parecían ocupar un lugar digno de mención. En Cartografía personal, Lafforgue vuelve a exponer su defensa de ambas instituciones (2005: 75-77; 157-158, nota 3) y se empeña en demostrar la continuidad (una suerte de hermandad) de la crítica argentina.

45. La reseña al segundo volumen, firmada por Héctor Schmucler en el número 28 de Los libros, no aporta grandes novedades con respecto al esquema evaluativo fijado por Rosa para el primero. Schmucler insiste en la ausencia de homogeneidad, recorre los artículos describiendo sus marcos metodológicos, y elogia con énfasis la contribución de dos críticos: N. Rosa y R. Piglia. Ese número 28 aparece en septiembre de 1972, un momento de agitación política referida a la masacre de Trelew. Contiene una sagaz encuesta sobre la tarea crítica a la que responden Ford, Gregorich, Ludmer, Núñez y Piglia (3-7), y una apasionante polémica entre Blas Matamoro y Nicolás Rosa sobre la crítica borgiana que desborda ampliamente el tema y se adentra en cuestiones de teoría de la literatura y filosofía del lenguaje (19-24), otro ejemplo del vuelo metódico postulado por algunas lecturas.

46. Salvo en el caso ya citado de Cortázar y de Rayuela (1963), la novela que representaba "una verdadera división de las aguas en el circuito de producción y de lectura de esos años" (Prieto 1983: 892).

47. Lafforgue reacciona con orgullo herido a esa afirmación y trata de responder largamente a Panesi en su libro de 2005 (100-108).

48. El artículo, que no se priva de los habituales biografemas de la crítica local caros a Rosa, se reproduce corregido y aumentado en Políticas de la crítica (1999: 321-347).

49. El gesto no es nuevo, por supuesto. Ya en 1981, en el prólogo a los dos volúmenes sobre la crítica contemporánea a su cargo (CEAL), Nicolás Rosa elegía aquellos discursos que correspondían al proclamado ideal de autonomía con respecto al objeto, y clasificaba a una serie de críticos convocados para participar en esos tomos. El corpus estudiado no contenía sólo obras argentinas; los críticos, en cambio, eran todos locales. En la lista se encuentran varios de los que habían colaborado en la empresa de Lafforgue (Barrenechea, Jitrik, Rivera, Rosa mismo, Ludmer, Sarlo), así como otros que representaban tendencias ligadas a las ciencias humanas, o voces "excéntricas" (Castagnino, Prieto, Viñas, Rest, Massotta, Germán García). El trabajo fue reproducido, con un mayor desarrollo sobre Jaime Rest, en Los fulgores del simulacro (1987), cuyo texto inaugural ("Estos textos, estos restos", 9-18) presenta posiciones muy radicalizadas de Rosa en lo que concierne el lenguaje de la literatura y la condición ficcional de la crítica.

\section{RESÚMENES}

En 1969 aparece el primer tomo de la compilación crítica Nueva novela latinoamericana, editado por Paidós (Jorge Lafforgue comp.) de Buenos Aires, seguido en 1972 por un segundo tomo 
dedicado a la narrativa argentina. El artículo estudia el contexto de excepción en que se publicaron esos volúmenes siguiendo tres parámetros: la reciente eclosión de la escritura continental, la situación de la literatura argentina, y el despunte de lenguajes críticos modelizados por la teoría. El trabajo de análisis muestra la coexistencia de una notable variedad de discursos especializados y subraya las tensiones que caracterizaban el caso argentino. Se cierne así el lugar de la obra dentro de un ciclo de reconocida efervescencia cultural y en relación con el afianzamiento ulterior de ciertos discursos críticos. Antológicos y pioneros a la vez, los volúmenes de Lafforgue proponen, a pesar de sus limitaciones, una síntesis elocuente en un momento de cambio.

1969 est l'année de la parution de Nueva novela latinoamericana 1, premier volume de la compilation de travaux critiques préparée par Jorge Lafforgue pour Paidós de Buenos Aires, qui fut suivi en 1972 par un deuxième tome dédié à la littérature argentine. L'article étudie le contexte d'exception dans lequel ces livres virent le jour suivant trois axes : l'éclosion de l'écriture du sous-continent peu avant ces mêmes années, la situation de la littérature argentine, et l'éveil de langages critiques de portée théorique. L'analyse montre la coexistence de discours spécialisés très divers et souligne les tensions qui parcouraient le champ littéraire argentin. On délimite ainsi la place qu'a pu occuper la compilation dans une conjoncture caractérisée par une notoire effervescence culturelle ainsi que par rapport à l'ultérieure consolidation des discours critiques. Les volumes de Lafforgue sont des ouvrages à la fois anthologiques et pionniers ; ils proposent, malgré certaines limitations, une synthèse éloquente dans un moment de transition.

Nueva novela latinoamericana 1 was edited in 1969 as the first volume of a critical articles compilation prepared by Jorge Lafforgue for Paidós of Buenos Aires; it was followed in 1972 by a second volume on argentine literature. This article studies the exceptional context in which those works came to daylight following three main axes: the rise of a powerful Latin American narrative short before then, the situation of argentine literature, and the surge of new critical discourses of theoretical inspiration. Several specialised languages coexist at the time; the article shows by which tensions the argentine literary field was then dominated. The Lafforgue's volumes are thus replaced in the frame of a very eventful cultural period and their relationship to the evolution of critical discourses is emphasized. These books are at the same time anthological and pioneer's work; in spite of some limitations they display a valuable synthesis built in a challenging moment.

\section{ÍNDICE}

Mots-clés: Nueva novela latinoamericana 1 et 2, contextes littéraires, roman argentin, débats critiques.

Palabras claves: Nueva novela latinoamericana 1 y 2, contextos literarios, narrativa argentina, debates críticos.

Keywords: Nueva novela latinoamericana 1 and 2, literary contexts, argentine novel, critical debates.

\section{AUTOR}

\section{TERESA ORECCHIA HAVAS}

Université de Caen

orecchia-havas@wanadoo.fr 